\title{
CORONARY ARTERY CATHETERIZATION DURING THORACIC AORTOGRAPHY
}

\author{
BY \\ A. M. JOHNSON AND WILLIAM D. LOGAN \\ From the Cardiac Department, Guy's Hospital \\ Received December 20, 1957
}

Ever since the introduction of retrograde aortic catheterization for the purpose of radiological demonstration of the thoracic aorta and its branches, the importance of correct positioning of the catheter tip before injection of opaque material has been emphasized. Several workers have stated the optimal position as being a short distance above the aortic valve.

The importance of fluoroscopic demonstration that the tip lies free in the main aortic stream at this site was stressed by Pearl et al. (1950), who suggested as aids to correct positioning, the sensation of resistance to the catheter at the aortic valve and the fluoroscopic demonstration of buckling of the catheter when the valve is reached: they reported that the left ventricle might be entered at this time and mentioned that "a forceful systolic impulse" might be transmitted to the operator's hand along the catheter. Zimmerman et al. (1950), who performed retrograde aortic catheterization through the left ulnar artery, found it impossible to enter the left ventricle from the aorta in five normal subjects. By selecting patients with aortic regurgitation, however, they succeeded in eleven of them and obtained pressure records. One showed ventricular premature contractions, while another had runs of ventricular tachycardia: in both, sinus rhythm was restored "by moving the tip of the catheter." One patient, with rheumatic aortic and mitral disease, during the attempt to move the catheter into the left ventricle suddenly complained of substernal pain and developed ventricular fibrillation from which he died in fifteen minutes: it was thought probable that the catheter had occluded a coronary ostium.

Zimmerman et al. (1951) later reported left ventricular catheterization by the same technique, for the purpose of studying cavity potentials in the ventricle. Eight syphilitic and two hypertensive cases of aortic regurgitation were studied and in six of these the left ventricle was entered. The position of the tip of the catheter was determined by fluoroscopy, by the increase in voltage of the cardiogram when the catheter tip entered the cavity of the left ventricle, and by observing the form of the pressure curve. That the latter criterion may be grossly misleading is shown by the present report.

Brodén et al. (1949) pointed out how easily the catheter may "glide into one of the coronary arteries," as happened in one of their cases where the right coronary artery was entered and injected with opaque fluid without untoward effect except for slight tachycardia. Jönsson et al. (1951), discussing thoracic aortography for the demonstration of patent ductus arteriosus and coarctation, state that the catheter tip "may fasten in the orifice of one of the coronary arteries, with perhaps fatal results."

Helmsworth et al. (1950) reported their attempts at coronary arteriography in six patients, two of whom died following repeated injection of contrast medium. As DiGuglielmo and Guttadauro (1952) indicate in their monograph on coronary arteriography, such repeated injections constitute a series of periods of myocardial anoxia. 
Pressure measurements during aortography may clearly be of value. When, for example, a catheter has been introduced into the aorta for the purpose of radiological demonstration of a persistent ductus, the ductus itself may be traversed during the manipulations and a record of pulmonary arterial pressure is then a useful and perhaps crucial piece of information. Johnson et al. (1957) in a recent assessment of the uses of thoracic aortography, point out that "in occasional instances hæmodynamic data with reference to the left ventricle may be obtained when the catheter tip slips easily into the left ventricle." This occurred in one of eighteen cases studied and left ventricular and aortic pressures were recorded. The propriety of attempting to enter the left ventricle in this way is seriously questioned in the light of the present case report. Thoracic aortography may now find widening application to the problems of coronary artery disease, and a recent report by Thal et al. (1957) illustrates this trend.

For these reasons we have felt it important to report a case in which, during aortography for demonstration or exclusion of a persistent ductus arteriosus in a girl with proven pulmonary stenosis, pressure records were misleading and were largely the cause of failure to recognize that the catheter had entered the right coronary artery. It is thought probable that the misleading nature of pressure waves obtainable in the coronary artery may not be widely recognized.

\section{CASE RePORT}

A girl, aged ten, had undergone right heart catheterization two years before, which confirmed a clinical diagnosis of pulmonary valve stenosis with closed septa. Pressures were $80 / 4 \mathrm{~mm}$. $\mathrm{Hg}$ in the right ventricle and $12 / 8 \mathrm{~mm}$. in the pulmonary artery. Blood oxygen estimations, however, suggested the coexistence of persistent ductus arteriosus and it was decided to perform aortography to confirm or exclude this diagnosis.

Under general anæsthesia, a No. 7 Cournand catheter was introduced into the left brachial artery and advanced under fluoroscopic control. After a few passages down the descending aorta the catheter entered the ascending aorta and was advanced, without apparent resistance, to a point near the right cardiophrenic angle, well below the expected region of the aortic valve. Here an atrial wave form was observed on a pressure recording. Slow withdrawal of the catheter then resulted in a sudden change to ventricular wave form and finally a return to aortic pressure waves as observed on the inward passage (Fig. 1). The finding of these atrial and ventricular pressures suggested that the catheter had entered the left ventricle and left atrium or even, through a ventricular septal defect, the right ventricle and right atrium. In retrospect, it is obvious that the catheter position was incompatible with these suggestions, but at the time the sequence was repeated thrice by advancing and withdrawing the catheter and finally it was decided to inject $10 \mathrm{ml}$. of 70 per cent diaginol at the "atrial" site. During the subsequent catheter withdrawal the electrocardiogram, which had hitherto remained unchanged, showed bursts of rapid irregular idioventricular rhythm. This ceased when the catheter was withdrawn further, into the aorta, but there was now S-T depression in lead I, the monitored lead at the time. X-ray films taken showed dense filling of the right coronary artery with an intense blush, indicating capillary filling, in the area of myocardium supplied (Fig. 2A). After an interval of ten minutes the catheter tip was positioned about $3 \mathrm{~cm}$. above the aortic valve and, with simultaneous carotid compression, $30 \mathrm{ml}$. of 70 per cent diaginol was injected rapidly. A satisfactory aortogram was obtained and, again, right coronary artery filling was seen (Fig. 2B). No ductus arteriosus was shown. There was a sinus tachycardia at a rate of 144 a minute, and marked S-T depression in leads I and aVL and S-T elevation in leads III and aVF.

Study of the pressure records showed that insertion of the catheter into the coronary artery was followed on the three occasions by a rise of aortic pressure. This returned to the initial normal level when the catheter, following the third withdrawal, was left free in the aorta for some minutes, but rose again when the catheter was finally reinserted and $10 \mathrm{ml}$. diaginol was injected. There was a further rise after the second injection which filled the right coronary artery from the aorta. The initial aortic pressure (from midthoracic level) was $135 / 71 \mathrm{~mm}$., the final pressure $159 / 107 \mathrm{~mm}$. Hg.

Subsequent cardiographic progress indicated posterior myocardial infarction (Fig. 3) and the clinical course was compatible with this. Though she experienced no pain and there was neither hypotension nor evidence of heart failure, she was febrile to $100 \cdot 6^{\circ} \mathrm{F}$. on the next day, with gradual return to normal by the eighth day. Blood counts, previously normal, showed a leucocytosis of 13,200 (polymorphs, $72 \%$ ) on the following day, and fell to a normal total count by the fourth day, though the polymorphs were still relatively increased at the tenth day. The E.S.R. (Westergren) rose to a peak of $25 \mathrm{~mm}$. in one hour by the fifth day and returned to normal by the tenth day. Clinically, recovery appeared complete. 


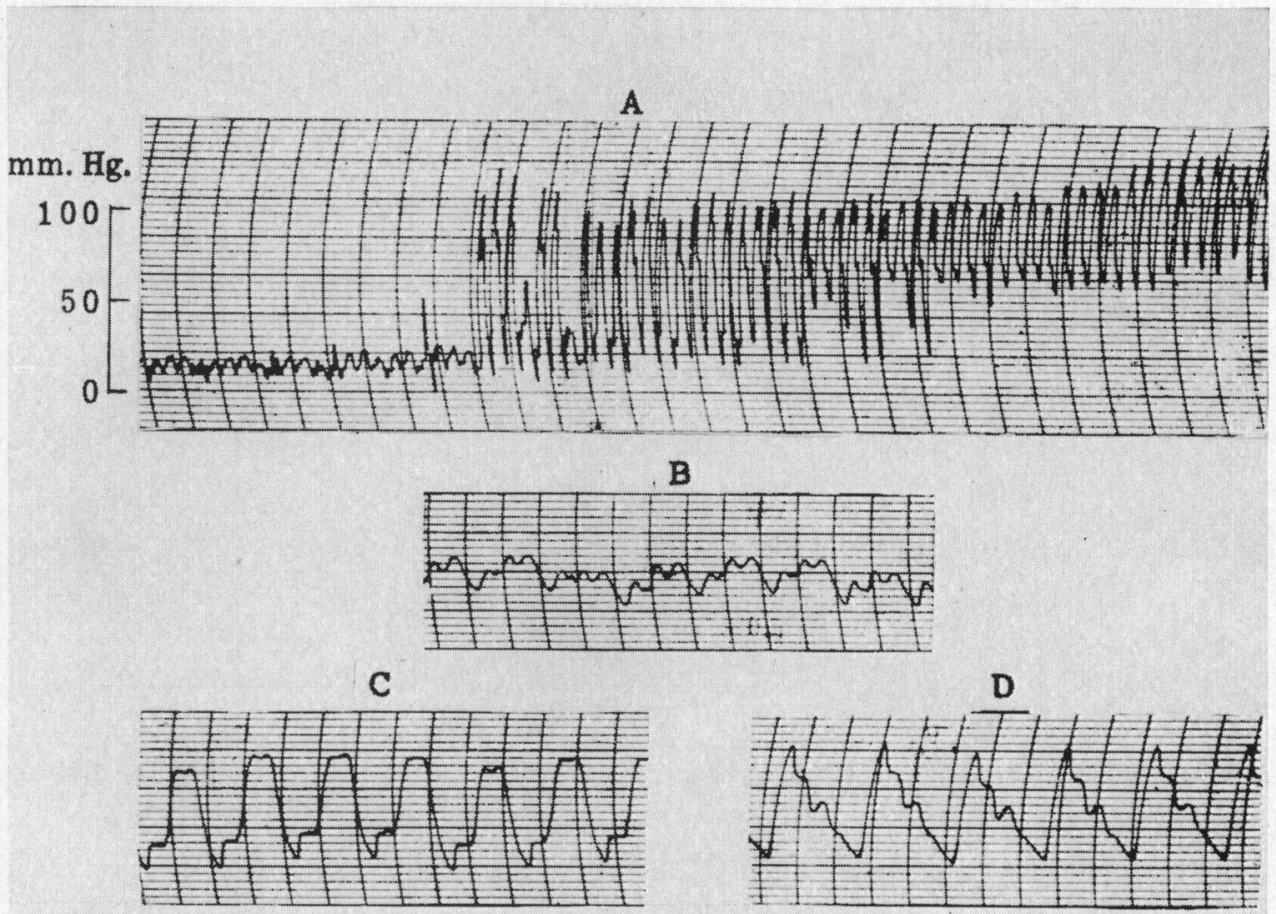

Fig. 1.-(A) Pressure record during withdrawal from wedge position in right coronary artery to aorta. (B), (C), and (D). "Atrial", "ventricular", and aortic wave forms respectively, at different sensitivity ranges.
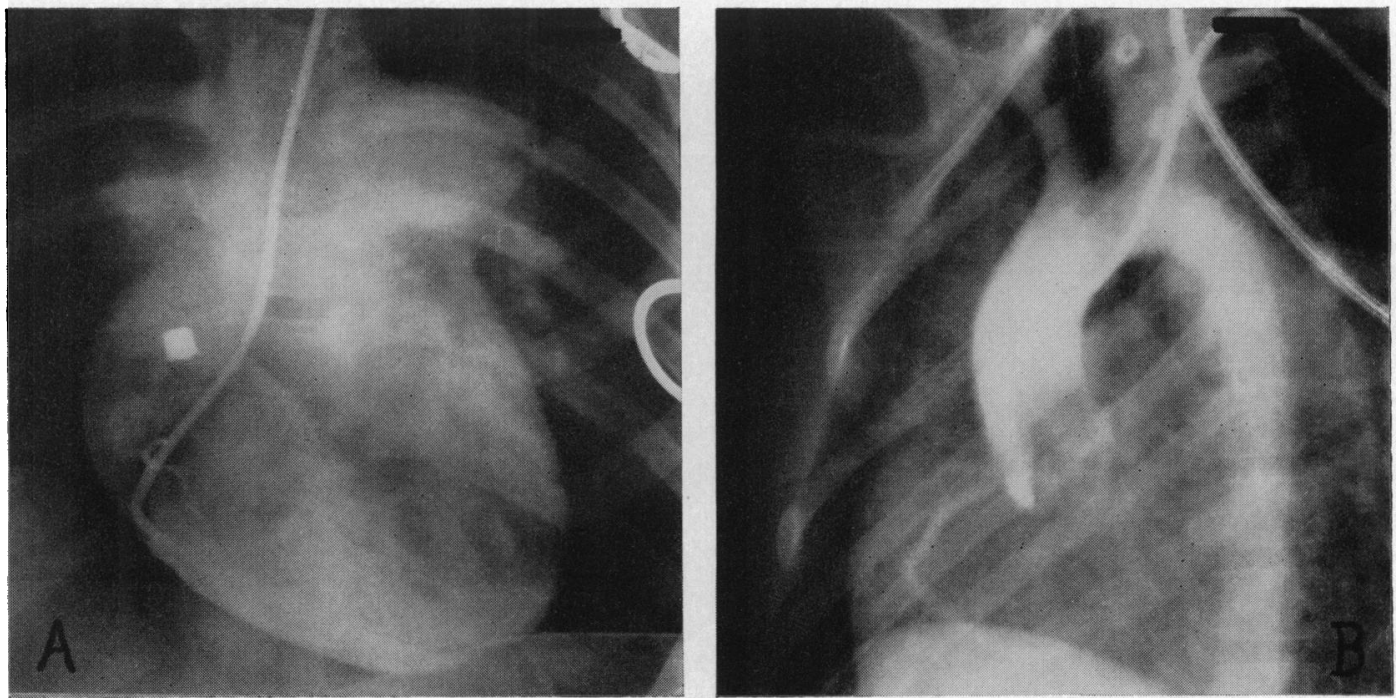

FIG. 2.-(A) Injection from catheter lying in the right coronary artery, showing dense concentration of opaque fluid in the area of myocardium supplied. (B) Injection into the ascending aorta, showing further filling of the right coronary artery. 


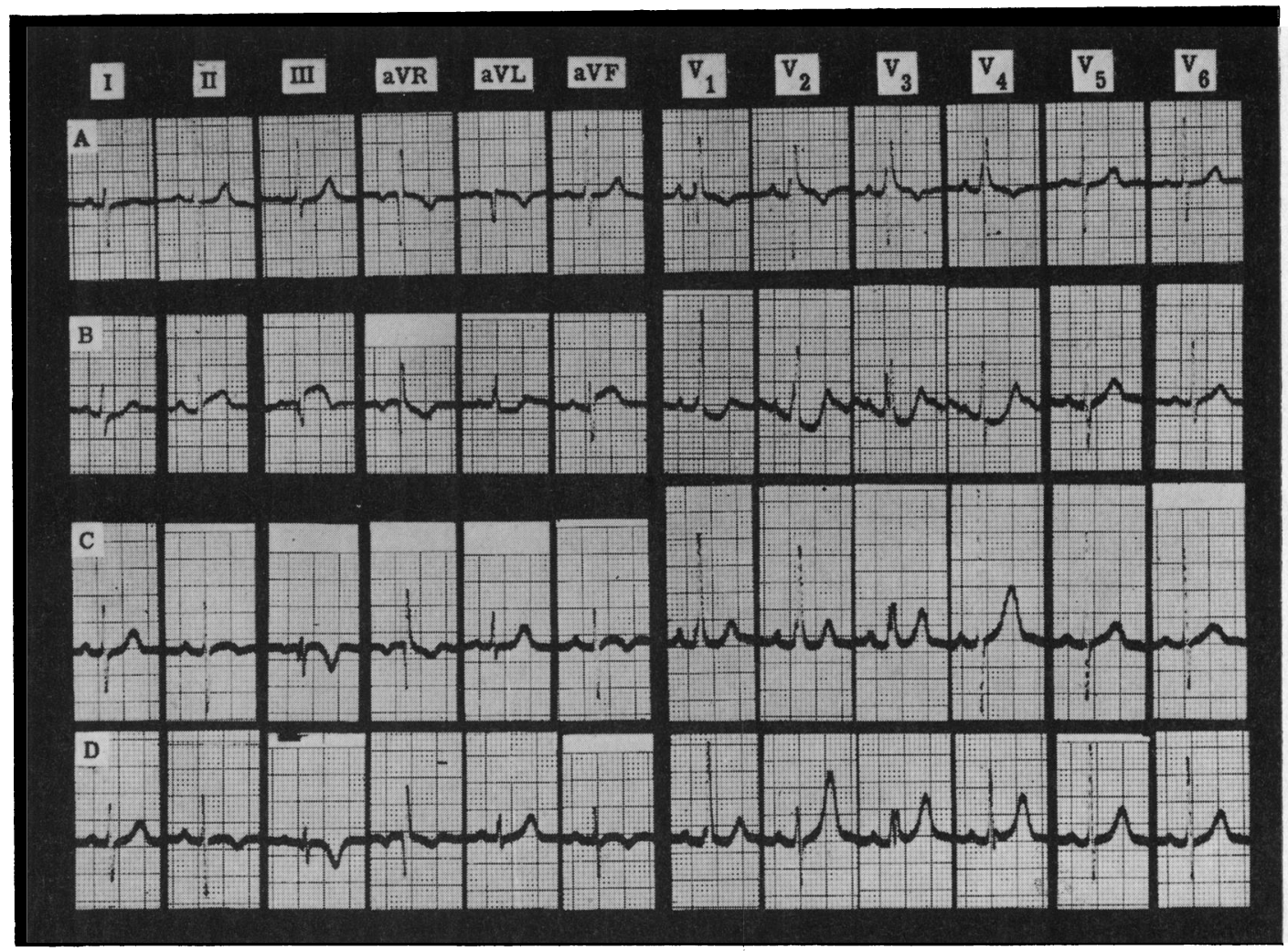

FIG. 3.-Serial electrocardiograms, (A) eight days before aortography; (B) on the day following aortography; (C) nine days after aortography; (D) three weeks after aortography.

\section{Discussion}

It is paradoxical that the inclusion of pressure records during this procedure should have obscured the fact, obvious in retrospect, that the right coronary artery had been catheterized. Clearly, an awareness that such pressure wave forms may be recorded from the coronary artery is of the first importance practically and would, in this instance, have prevented the major insult to the myocardium.

It is of interest to consider how such pressure waves may be found in this situation. It is recognized that catheterization of the coronary sinus in man may yield wave forms of magnitude and shape closely, if not exactly, resembling ventricular forms (Culbertson et al., 1949; Gregg, 1950; Miller et al., 1953; Harris and Summerhayes, 1955).

Gregg (1950) has shown that a fall in central coronary artery pressure results in increased peripheral resistance in the coronary circulation. It may be that the catheter, at one stage in its advance down the coronary artery, occluded it only during systole, the mean pressure beyond this point falling and coronary arteriolar constriction occurring. The situation may then have resembled experimental conditions that have been described for the study of intramyocardial pressures.

Johnson and DiPalma (1939) imbedded isolated sections of carotid artery at varying depths in the left ventricular myocardium and showed that pressure changes within these segments were of ventricular form. Gregg and Eckstein (1941) showed that these pressures were subject to gross artefacts from distorsions and movements of the section, and attempted to avoid such artefacts by protecting the section from such influences with a fenestrated tube. They found that pressures within such protected sections approximated closely to the left ventricular pressures, despite the 
important, variable, and unknown quantity of local muscle stretch due to the presence of the section within it. Because of this unknown factor they concluded that the method, while useful to give directional changes of pressure during the cardiac cycle, was not suitable for measuring those changes. Nevertheless, pressure waves closely approximating the ventricular pressures in magnitude and form were demonstrated. Gregg (1950) has also shown that, following experimental occlusion of a coronary artery in the dog, the pressure waves in the same vessel distal to the block, following development of collateral circulation, may be of central coronary or aortic type if the collaterals are predominantly superficial, but of ventricular form if the collaterals are deeply buried in the myocardium.

Further work by Johnson (1945), who used a similar method in attempts to measure intramyocardial pressure, indicated that one of the factors influencing this was the resistance to muscle shortening. His findings suggested that, with increasing aortic resistance, contractions of the left ventricle become more nearly isometric, and intramuscular pressure approaches a measure of the full force of contraction. In the case here recorded it may be relevant that the catheter was in the wall of the right ventricle and that there was severe pulmonary stenosis.

The finding of atrial pressure when the catheter was completely "wedged" suggests that the resulting complete cessation of coronary flow may cause arteriolar relaxation, possibly as the result of local anoxia and metabolite accumulation (Gregg, 1950), so that right atrial pressures are transmitted to the catheter in a manner analogous to the obtaining of pulmonary "wedge" pressures. We have subsequently catheterized the right coronary artery in the dog and have found atrial pressures when the catheter was completely wedged.

The significance of the systemic hypertension that developed during the procedure is uncertain.

\section{SUMMARY}

The dangers of coronary artery catheterization and of repeated injections of radio-opaque material, which will enter the coronary tree in some concentration, are reiterated.

A case is reported in which pressure records from the right coronary artery, inadvertently catheterized, were misinterpreted as indicating the presence of the catheter in ventricle and atrium in turn.

The mechanisms by which such pressures may be developed in the coronary artery are discussed, and the practical importance of recognizing that such pressure wave forms may be found with the catheter so dangerously malpositioned is stressed.

The propriety of searching for the aortic valve orifice, or of any other exploration by retrograde aortic catheter in the region of the valve, is questioned in the light of this case.

We are grateful to Dr. P. R. Evans for permission to publish details of his case and to Dr. Charles Baker for encouragement and advice in the preparation of this report.

\section{REFERENCES}

Brodén, B., Jönsson, G., and Karnell, J. (1949). Acta Radiol., 32, 498.

Culbertson, J. W., Halperin, M. H., and Wilkins, R. W. (1949). Amer. Heart J., 37, 942.

DiGuglielmo, L., and Guttadauro, M. (1952). Acta Radiol., Supp. 97.

Gregg, D. E. (1950). Coronary Circulation in Health and Disease. Henry Kimpton, London.

, and Eckstein, R. W. (1941). Amer. J. Physiol., 132, 781.

Harris, P., and Summerhayes, J. L. V. (1955). Brit. Heart J., 17, 453.

Helmsworth, J. A., McGuire, J., and Felson, B. (1950). Amer. J. Roentgenol., 64, 196.

Johnson, J. B., Lawlah, J. W., McFadden, F., and Dyer, J. F., Jr. (1957). Amer. Heart J., 53, 40.

Johnson, J. R. (1945). Fed. Proc., 4, 37.

-, and DiPalma, J. R. (1939). Amer. J. Physiol., 125, 234.

Jönsson, G., Brodén, B., and Karnell, J. (1951). Acta Radiol., Supp. 89.

Miller, G. Kaplan, B. M., and Katz, L. N. (1953). Amer. Heart J., 46, 857.

Pearl, F., Friedman, M., Gray, N., and Friedman, B. (1950). Circulation, 1, 1188.

Thal, A., P., Lester, R. G., Richards, S. R., and Murray, M. J. (1957). Surg., Gynec., Obstet., 105, 457.

Zimmerman, H. A., and Hellerstein, H. K. (1951). Circulation, 3, 95.

- Scott, R. W., and Becker, N. O. (1950). Circulation, 1, 357. 